\title{
Modeling the Flash Rate of Thunderstorms. Part I: Framework
}

\author{
Johannes M. L. DAhL,* HARTMUt HÖLleR, AND UlRich SCHUMANN \\ Institut für Physik der Atmosphäre, Deutsches Zentrum für Luft- und Raumfahrt, Oberpfaffenhofen, Germany
}

(Manuscript received 10 November 2010, in final form 23 May 2011)

\begin{abstract}
In this study a straightforward theoretical approach to determining the flash rate in thunderstorms is presented. A two-plate capacitor represents the basic dipole charge structure of a thunderstorm, which is charged by the generator current and discharged by lightning. If the geometry of the capacitor plates, the generator-current density, and the lightning charge are known, and if charging and discharging are in equilibrium, then the flash rate is uniquely determined.

To diagnose the flash rate of real-world thunderstorms using this framework, estimates of the required relationships between the predictor variables and observable cloud properties are provided. With these estimates, the flash rate can be parameterized.

In previous approaches, the lightning rate has been set linearly proportional to the electrification rate (such as the storm's generator power or generator current), which implies a constant amount of neutralization by lightning discharges (such as lightning energy or lightning charge). This leads to inconsistencies between these approaches. Within the new framework proposed here, the discharge strength is allowed to vary with storm geometry, which remedies the physical inconsistencies of the previous approaches.

The new parameterization is compared with observations using polarimetric radar data and measurements from the lightning detection network, LINET. The flash rates of a broad spectrum of discrete thunderstorm cells are accurately diagnosed by the new approach, while the flash rates of mesoscale convective systems are overestimated.
\end{abstract}

\section{Introduction}

In recent years, many details about cloud electrification have been revealed on the scale of individual hydrometeors (Dash et al. 2001; Saunders 2008), as well as on the cloud scale, based on measurements (Stolzenburg and Marshall 2009) and numerical simulations (e.g., Mansell et al. 2002; Mansell et al. 2005). However, the fundamental questionwhich cloud parameters determine the lightning rate in thunderstorms - has not satisfactorily been answered yet (e.g., Boccippio 2002; Yoshida et al. 2009). With this paper, we intend to contribute an answer to this question.

An intuitive approach to diagnosing the lightning frequency of a thunderstorm is to set the lightning frequency

\footnotetext{
* Current affiliation: Department of Marine, Earth, and Atmospheric Sciences, North Carolina State University, Raleigh, North Carolina.

Corresponding author address: Dr. Johannes Dahl, Dept. of Marine, Earth, and Atmospheric Sciences, North Carolina State University, Campus Box 8208, Raleigh, NC 27695-8208. E-mail: johannes_dahl@ncsu.edu
}

proportional to the rate at which the cloud becomes "electrified" (e.g., Williams 1985; Price and Rind 1992; Blyth et al. 2001; Yoshida et al. 2009). This electrification rate may be expressed in terms of the rate of increase of electrostatic field energy (e.g., Williams 1985; Price and Rind 1992; Yoshida et al. 2009) or, alternatively, in terms of the rate of increase of the electric charge (e.g., Blyth et al. 2001, and also Yoshida et al. 2009). Consequently, there are at least two ways to diagnose the lightning rate: either via the storm generator power (rate of increase of electrostatic energy) or via the storm generator current (rate of increase of electric charge). As detailed in Boccippio (2002), these approaches are inconsistent with one another. This discrepancy was carefully analyzed by Boccippio (2002), but it has not been solved.

The notion of relating the lightning frequency to the electrical power of a thunderstorm dates back to the 1960s when Vonnegut (1963) suggested that the power of a storm can be determined if the flash rate and the flash energy are known. This idea was further developed by Williams (1985), who proposed that the flash rate and the storm power are linearly proportional to each other. Based on this idea and after several assumptions mainly 
about storm geometry, he found that the lightning rate varies as the fifth power of the cloud-top height. This result was condensed into a parameterization of the lightning rate of continental thunderstorms by Price and Rind (1992), whose results support the dependence of the lightning rate on the fifth power of the cloud-top height. Another lightning-frequency parameterization, based on the same assumptions that Williams (1985) and Price and Rind (1992) used, has recently been put forth by Yoshida et al. (2009).

Aside from the proportionality of the flash rate to generator power and generator current, correlations were found between the lightning frequency and the convective rainfall rate (e.g., Chéze and Sauvageot 1997; Tapia et al. 1998). In their essence, all of these parameterizations are "single parameter" approaches as they relate the flash rate to a single predictor, and as will be shown they are all physically inconsistent with each other. In this study, an attempt is made to remedy these discrepancies, and it is shown that there is no preferred quantity (such as storm generator power or charging current) to predict the flash rate. A formula describing the lightning frequency is presented, which contains the single-parameter approaches as a limiting case.

Specifically, the goals are to

- develop a simple theoretical framework to understand what determines the lightning rate,

- clarify the implications of single-parameter approaches to predict the lightning rate and the inconsistencies between them,

- present estimates that relate the electrical properties of the cloud to observable cloud properties, and

- test the predictions by the new method using polarimetric radar data and lightning measurements.

The new approach is developed and compared to singleparameter approaches from a theoretical perspective in section 2. In section 3, this approach is specified using estimates relating cloud-electricity parameters to observable cloud properties, making the new framework applicable to real-world convective clouds. A test of the new parameterization, using lightning measurements and polarimetric radar data, is presented in section 4. A discussion of the results is offered in section 5, and a summary is provided in section 6 .

\section{The flash rate}

Before considering the processes that determine the flash rate, we briefly review how cloud charging is achieved in thunderstorms.

The basic charging of a thundercloud is tied to collisions between graupel pellets with ice crystals and subsequent differential sedimentation (e.g., Takahashi 1978; Saunders 2008). The direction of the charge transfer during a collision is determined by environmental factors such as temperature and liquid-water content, and is ultimately tied to the depositional growth rates of the colliding particles. The underlying theory has been put forth by Baker et al. (1987) and was further developed by Dash et al. (2001). Saunders (2008) offers a thorough review of this theory. These collisions and the subsequent sedimentation of the graupel particles result in a basic electric "tripole" charge structure in the thunderstorm. A main positively charged region is found in the upper portions of the storm where ice crystals dominate, and a main negatively charged region is found somewhat above the 263-K isotherm due mainly to charged graupel particles. A weaker positively charged region exists in the lower portions of the cloud (Williams 1989).

In this study only this noninductive mechanism is considered, though inductive charging and transport of charged particles have been suggested to contribute to the overall charge structure as well (MacGorman and Rust 1998; Saunders 2008). These contributions may result in departures from the simple tripole charge structure (Stolzenburg et al. 1998).

In the rest of this section a simple theoretical framework is provided, which yields an expression for the flash rate based on a two-plate capacitor model. Also, previous approaches and their implications are discussed.

\section{a. The flash-rate equation}

Once charge separation is occurring, an electric field builds between the space charge regions. If the electric field reaches a critical strength, a discharge occurs. For the moment, it is assumed that lightning is the only discharge mechanism.

The time $T$ for this initial charging is related to the rate at which the vertical component of the electric field $E$ increases and to the critical electric field strength $E_{c}$ :

$$
E_{c}=\int_{0}^{T} \frac{\partial E}{\partial t} d t
$$

At time $T$ the critical field strength is reached and a discharge occurs. The strength of the discharge (i.e., the amount of charge transferred) determines the degree to which the electrostatic field is neutralized. In this approach, details such as discharge duration and the temporal development of the current in the lightning channel are not treated separately but are contained in the net charge neutralized during the discharge.

Usually, only a fraction of the electric field is neutralized, and it is this fraction that needs to be replenished before the next flash can occur. If $\bar{E}$ is the electric 
field after the discharge, the field strength that needs to be restored $(\Delta E)$ is given by

$$
E_{c}-\bar{E}=\Delta E=\tau \frac{\partial E}{\partial t},
$$

where $\tau$ is the time required to rebuild the field. The charging rate $(\partial E / \partial t)$ has been assumed to be constant between two discharges. The discharge rate $f$ is then given by

$$
f=\frac{1}{\tau}=\frac{1}{\Delta E} \frac{\partial E}{\partial t} .
$$

This equation may be rewritten as

$$
\frac{\partial E}{\partial t}-f \Delta E=0,
$$

which implies a balance between charging and discharging. The charging current constantly attempts to push the field strength beyond the critical threshold, which is prevented by the lightning current that acts to weaken the electric field. This approach diagnoses an instantaneous flash rate with the assumption that the critical charge has been achieved already and that the critical field strength is time independent. This seems to be in contradiction to situations where a convective cell may become electrically charged, but the charging rate is so weak that the critical field strength is not reached before the cell dissipates. This contradiction is handled automatically in this approach. In such a situation, the convective cloud would be characterized either by a low charging rate or by a large field neutralization, or both [see Eq. (3)]. If these quantities are diagnosed correctly, this will result in a predicted time interval between two flashes that is larger than the cell's lifetime. Although the flash rate is nonzero, the cell would practically never produce a lightning discharge [see also Williams (1985); p. 6018].

The quantity $\Delta E$ may also be expressed with the aid of a so-called neutralization efficiency ${ }^{1} \eta$ so that

$$
\Delta E=\eta E_{c}
$$

where

$$
\eta=\frac{E_{c}-\bar{E}}{E_{c}} .
$$

Hence, the discharge rate is given by

\footnotetext{
${ }^{1}$ Introducing this quantity was motivated by Boccippio (2002) who used a so-called charge-removal efficiency.
}

TABLE 1. Possible choices for $\Psi$ and the meaning of their time derivatives.

\begin{tabular}{llll}
\hline \hline$\Psi$ & Meaning of $\Psi$ & $\frac{\partial \Psi}{\partial t}$ & Term for $\frac{\partial \Psi}{\partial t}$ \\
\hline$Q$ & Electric charge & $\frac{\partial Q}{\partial t}=I$ & Electric current \\
$W$ & Electrostatic energy & $\frac{\partial W}{\partial t}=P$ & Electric power \\
$\sigma$ & Electric charge & $\frac{\partial \sigma}{\partial t}=j$ & $\begin{array}{c}\text { Electric current } \\
\text { per area }\end{array}$ \\
$E$ & Electrostatic field & $\frac{\partial E}{\partial t}$ & None \\
\hline
\end{tabular}

$$
f=\frac{1}{\eta E_{c}} \frac{\partial E}{\partial t} .
$$

Obviously, the larger $\eta$ (i.e., the stronger the discharge), the larger the electrostatic field that needs to be restored before the next flash can occur, and the smaller the flash frequency. For instance, $\eta=1$ implies that the entire field has been neutralized during the discharge.

Instead of the electrostatic field, any other quantity may be chosen that uniquely describes when breakdown takes place, such as the charge or charge density. If this general quantity is denoted with $\Psi$, the flash-rate equation may be written as

$$
f=\frac{1}{\Delta \Psi} \frac{\partial \Psi}{\partial t}
$$

The time rate of change of $\Psi$ may be thought of as "electrification rate" of the storm. Equation (4) then takes the form

$$
\frac{\partial \Psi}{\partial t}-f \Delta \Psi=0 .
$$

Some possible choices for $\Psi$ are presented in Table 1. Using these variables, Eq. (9) may be written as

$$
f=\frac{I}{\Delta Q}=\frac{P}{\Delta W}=\frac{j}{\Delta \sigma}=\frac{1}{\Delta E} \frac{\partial E}{\partial t}=\ldots .
$$

The equivalence of these formulations is supported by their dimensions:

$$
\begin{array}{ll}
{[\Delta Q]=\mathrm{C},} & {[I]=\mathrm{Cs}^{-1}} \\
{[\Delta W]=\mathrm{J},} & {[P]=\mathrm{J} \mathrm{s}^{-1}} \\
{[\Delta Q]=\mathrm{Cm}^{-2},} & {[j]=\mathrm{Cm}^{-2} \mathrm{~s}^{-1}} \\
{[\Delta E]=\mathrm{V} \mathrm{m}^{-1},} & {\left[\frac{\partial E}{\partial t}\right]=\mathrm{V} \mathrm{m}^{-1} \mathrm{~s}^{-1},}
\end{array}
$$

where $[Q]=1 \mathrm{~A} \mathrm{~s}=1 \mathrm{C}$. Equation (10) is thus dimensionally consistent.

To summarize the results of this section, we developed an expression that relates the flash frequency to the ratio 
of the charging rate and the discharge strength. The property of being a ratio implies that the numerator and the denominator are not uniquely determined (they only need to be linked to each other via the temporal derivative). This is the reason why either the electric charge (electric current), the electrostatic energy (electric power), or any other quantity in Table 1 may be used. Applied to simple electrostatic problems, it can be shown that after some algebraic manipulations any variable from Table 1 yields equivalent results (not shown).

\section{b. Single-parameter approaches}

We are now turning to a simpler formulation of the problem, which has frequently been used in the literature but which leads to physical inconsistencies. In the following, we explain why this is the case and how the approach just presented remedies these inconsistencies.

There are two frequently employed theoretical frameworks for determining the flash rate, as mentioned in the introduction and as discussed in Boccippio (2002) and Yoshida et al. (2009). The first framework is based on the proportionality of the flash rate and the charging current, where $f \propto I$. This stipulation is the foundation of the "flux hypothesis" put forth by Blyth et al. (2001) and Deierling et al. (2008). ${ }^{2}$ The other framework is based on a linear relationship between the flash rate and generator power, so that $f \propto P$ (e.g., Williams 1985; Price and Rind 1992; Yoshida et al. 2009). These approaches employ only one single predictor, namely the electrification rate. In terms of $\Psi$, the single-parameter approaches may be summarized by

$$
f_{\Psi} \propto \frac{\partial \Psi}{\partial t}
$$

As the flash rate has the unit $\mathrm{s}^{-1}$, the constant factor of proportionality is required to have the inverse unit of $\Psi$, so that

$$
f_{\Psi}=\frac{1}{\overline{\Delta \Psi}} \frac{\partial \Psi}{\partial t}
$$

In this case, $\overline{\Delta \Psi}$ is just the neutralization strength, which is treated as a constant in the single-parameter approaches. Note the formal similarity between Eqs. (12)

\footnotetext{
${ }^{2}$ Note, however, that the approach by Blyth et al. (2001) is dimensionally inconsistent [see their Eq. (1)]. They stipulate that $f \Delta Q \propto j$. While the left-hand side of this equation has the dimension of an electric current $([f \Delta Q]=\mathrm{A})$, the right-hand side has the dimension of a current density $\left([j]=\mathrm{A} \mathrm{m}^{-2}\right)$. Indirectly, this implies that there is a characteristic cross-sectional area of the updrafts that is identical for all storms.
}

and (8), which differ only in their treatment of the denominator. It is the constancy of the denominator in the single-parameter approaches that causes the problems.

The "generator power perspective" implies that $\Psi$ is equal to the electrostatic energy, $W$ (Williams 1985; Price and Rind 1992; Yoshida et al. 2009). We set $\Psi=$ $W$, and obtain

$$
f_{W}=\frac{P}{\overline{\Delta W}}
$$

where the time rate of change of $W$ has been expressed as electric power $P$ (Table 1 ). The discharge energy $\overline{\Delta W}$ is treated as a universal constant.

In the "generator current perspective," we set $\Psi=Q$ (e.g., Blyth et al. 2001; Deierling et al. 2008) and obtain

$$
f_{Q}=\frac{I}{\overline{\Delta Q}}
$$

where $I$ is the charging current and $\overline{\Delta Q}$ is the universally constant lightning charge. Yoshida et al. (2009) discuss both relationships, $f \propto I$ and $f \propto P$, though they used electrostatic energy rather than electric power. ${ }^{3} \mathrm{An}$ other possible choice for $\Psi$ is the charge per unit area $\sigma$, so that

$$
f_{\sigma}=\frac{1}{\overline{\Delta \sigma}} j
$$

where $j$ is the generator current density.

To see why these approaches are inconsistent with each other, we consider the predicted lightning charge for several choices of $\Psi$. For this purpose, two homogeneously charged, circular plates are employed (the top plate is positively charged and the bottom plate is negatively charged). In the spirit of Vonnegut (1963) and Williams (1985), the capacitor's width is assumed to covary with its depth. This assumption is only used for the moment to understand the qualitative behavior of the discharge magnitudes predicted by the singleparameter approaches. We introduce a length scale variable $l$ given by

$$
l=\frac{R}{\alpha}=\frac{d}{\beta},
$$

\footnotetext{
${ }^{3}$ Their reasoning suggests that they erroneously used energy instead of power, as did Price and Rind (1992). Setting $f \propto W$, while the lightning energy $\overline{\Delta W}$ is constant, is inconsistent. Stipulating an $f-W$ proportionality implies a global constant that has the unit of action (J s).
} 
where $R$ and $d$ are the plate radius and the plate-separation distance, respectively, and $\alpha$ and $\beta$ are constants.

To determine the lightning charge for $\Psi=W$, we consider

$$
\overline{\Delta W} \approx \Phi \Delta Q=\text { const }
$$

where $\Phi$ is the potential difference between the top and bottom plates. ${ }^{4}$ For the two-plate charge configuration, the voltage is given by (cf. Boccippio 2002, p. 1097)

$$
\Phi=\frac{\sigma}{\epsilon}\left(R+d-\sqrt{R^{2}+d^{2}}\right),
$$

where $\epsilon$ is the permittivity. Given the depth-width proportionality, the bracketed term scales with $l$, and so does $\Phi$. Then,

$$
\overline{\Delta W} \propto l \Delta Q=\text { const. }
$$

Upon rearranging, we find that

$$
\Delta Q \propto l^{-1}
$$

In other words, the charge per flash decreases as the size of the storm increases if $\overline{\Delta W}$ is to remain constant. This result holds if the lightning charge (energy) is small compared to the storm's total charge (energy), for we neglected the quadratic term in Eq. (20). However, the qualitative behavior remains unchanged if the quadratic term is retained. Similarly, the behavior of the lightning charge can be derived for other choices of $\Psi$, as summarized in Table 2. The result is that the lightning charge scales with geometry in quite different ways, depending on the selection for $\Psi$. Even if the charging

\footnotetext{
${ }^{4}$ As one of the reviewers pointed out, Eq. (17) is an approximation for small $\Delta Q$, because the lightning energy may be written as

$$
\begin{aligned}
\Delta W & =\int_{Q}^{Q+\Delta Q} \Phi d Q^{\prime} \\
& =\frac{Q}{C} \Delta Q+\frac{1}{2 C}(\Delta Q)^{2} \\
& =\Phi \Delta Q+\frac{1}{2 C}(\Delta Q)^{2},
\end{aligned}
$$

where $\Phi=Q C^{-1}$ was used ( $C$ is the capacitance and $Q$ the capacitor charge). Only for small discharge magnitudes the quadratic term in Eq. (20) may be neglected.
}

TABLE 2. Expressions for the flash rate for different choices of $\Psi$. The implied universal constant and the implied charge transfer per flash are also shown. Here, $l$ is a length scale that linearly varies with both the height and diameter of the storm.

\begin{tabular}{llll}
\hline \hline$\Psi$ & $\overline{f_{\psi}}$ & $\overline{\Delta \Psi}$ & $\Delta Q$ \\
\hline$Q$ & $f_{Q}=\frac{1}{\overline{\Delta Q}} \frac{\partial Q}{\partial t} \propto I$ & $\overline{\Delta Q}$ & $\Delta Q=\mathrm{const}$ \\
$W$ & $f_{w}=\frac{1}{\overline{\Delta W}} \frac{\partial W}{\partial t} \propto P$ & $\overline{\Delta W}$ & $\Delta Q \propto l^{-1}$ \\
$\sigma$ & $f_{\sigma}=\frac{1}{\overline{\Delta \sigma}} \frac{\partial \sigma}{\partial t} \propto j$ & $\overline{\Delta \sigma}$ & $\Delta Q \propto l^{2}$ \\
$E$ & $f_{E}=\frac{1}{\overline{\Delta E}} \frac{\partial E}{\partial t}$ & $\overline{\Delta E}$ & $\Delta Q \propto l^{2}$ \\
\hline
\end{tabular}

rate for all choices of $\Psi$ was correctly diagnosed for a given storm geometry, the predicted flash rate would ultimately differ because of the different discharge amplitudes. The constants, $\overline{\Delta W}, \overline{\Delta Q}$, etc., could be adjusted to yield identical lightning rates for a given storm, but as soon as the geometry changes, or if a storm with a different geometry is considered, the flash-rate predictions would diverge. The single-parameter approaches tacitly enforce a certain magnitude of lightning charge, which is merely a "by-product" of the choice of $\Psi$. This may result in an interesting side effect. For instance, if the flash rate is set proportional to the generator power, the lightning charge increases as the storm size decreases (Table 2). On the other hand, the charge required to create critical field strength decreases with storm size (e.g., Fig. 2a). Consequently, the lightning charge may exceed the charge in the thunderstorm (resulting in $\eta>1$ ). This leads to an underestimation of the flash rate and defies basic physics. ${ }^{5}$ Moreover, the variables that are treated as constants, such as lightning energy or lightning charge, are observed to vary substantially (e.g., Cooray 1997; Maggio et al. 2009), which invalidates the basic assumption underlying these approaches [Eq. (12)].

Synthesizing the results obtained thus far, the singleparameter approaches imply a constant discharge quantity for every flash (Table 2). These constants imply a certain amount of electric charge that is depleted by the flashes, which strongly depends on the geometry, and which differs for many choices of $\Psi$. In the new approach presented in the previous subsection, the $\Psi$ neutralization is allowed to vary. Then, the flash rate is described by the ratio of the charging rate and the discharge magnitude,

\footnotetext{
${ }^{5}$ From a mathematical perspective, this pattern of behavior is reflected in the quadratic equation for $\Delta Q$ that may be obtained from Eq. (19). Assuming an ideal capacitor where $W=Q^{2} /(2 C)$, and in addition that $W>0$ and $\Delta W<0$, the root of the quadratic equation becomes complex if $|\Delta W|>W$.
} 
independent of the choice for $\Psi$. This remedies the inconsistencies between the single-parameter approaches. The predictions of all these single-parameter approaches could be reproduced by Eq. (3), if the discharge strengths based on the predicted charge transfer from Table 2 were inserted into this equation. This implies that all the univariate approaches are included in the more general approach [Eq. (10)].

It follows that there is no single parameter that describes the flash rate best; all of them are inappropriate to describe the entire spectrum of storms, because the amount of neutralized $\Psi$ is not allowed to vary.

\section{c. The "fifth-power law"}

A famous offspring of the assumption that the flash rate linearly varies with storm power is the "fifth-power law," which states that the flash rate is proportional to the fifth power of the storm depth. It was demonstrated in the previous subsection that the predictions based on a single parameter are fundamentally flawed. The following items clarify which assumptions are required when deriving the fifth-power law. These are

- the flash rate varies linearly with storm power,

- the aspect ratio of all storms is the same, and

- the charge-flux velocity is linearly proportional to the storm depth (or width).

See Boccippio (2002) for a discussion about the validity of these assumptions. Note that the fifth-power relation may also be derived using the two-plate capacitor geometry (which is not repeated here for the sake of brevity).

Despite our concerns regarding the assumptions leading to fifth-power relations, observations by Williams (1985) and Yoshida et al. (2009) suggest that such a relation might exist, which will be addressed again in section 5 .

\section{d. Application to homogeneously charged plates}

To obtain quantitative results using the new approach, specification of the space charge distribution is necessary. The simplest model of the electrical structure of a thunderstorm arguably is represented by two circular, oppositely charged plates, which will be used herein. Figure 1 summarizes this charge geometry. The lightning current $I_{L}$ is given by

$$
I_{L}=f \Delta Q,
$$

and is balanced by the generator current. This balance between charging current and lightning current is consistent with Eq. (10), from which it follows that

$$
\frac{\partial Q}{\partial t}-f \Delta Q=I_{c}-I_{L}=0
$$

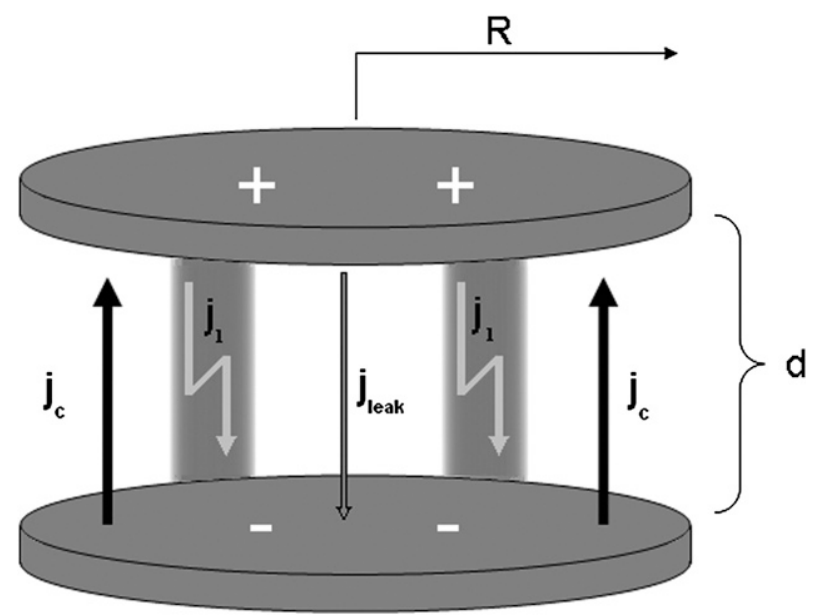

FIG. 1. Qualitative sketch of the capacitor used to model the space charge regions of a thunderstorm. The geometric parameters, $R$ and $d$, are shown, as well as the lightning current densities (light gray, lightning-shaped arrows), the generator current densities (black arrows), as well as a "leakage current density" associated with, e.g., precipitation currents. Plus and minus signs refer to the sign of the plate charge.

This means that if the charging current is known, the lightning current is known as well. To infer the flash rate, only the lightning charge needs to be prescribed. Based on Eq. (10), we express the flash rate as

$$
f=\frac{I}{\Delta Q}=j \frac{A}{\Delta Q}
$$

where $A$ is the plate area. ${ }^{6}$ Note that the capacitor plates may have an arbitrary shape (the circular shape in Fig. 1 was used only for simplicity). Apart from the charging rate $j$ and the lightning charge $\Delta Q$, the flash rate also depends on the area of the capacitor plates. To gain an understanding of this area dependency, it is instructive to isolate this effect by considering the response of the electrostatic field to a constant amount of charge that is neutralized (this constancy is not part of the new approach; it is merely employed here to clarify the influence of the plate area). Figure 2 a shows the dependence of the charge required to create an electrostatic field of $100 \mathrm{kV} \mathrm{m}^{-1}$ on the geometry of the capacitor. The larger the radius of the plates, the more charge is required to achieve critical field strength. This is because the field strength depends on the charge per unit area. Consequently, the response of the electrostatic field to a certain amount of charge that is removed from the

\footnotetext{
${ }^{6}$ Using, e.g., the electrostatic field, $\Psi=E$ results in a somewhat complicated equation for the flash rate, which after some manipulations reduces to Eq. (26).
} 

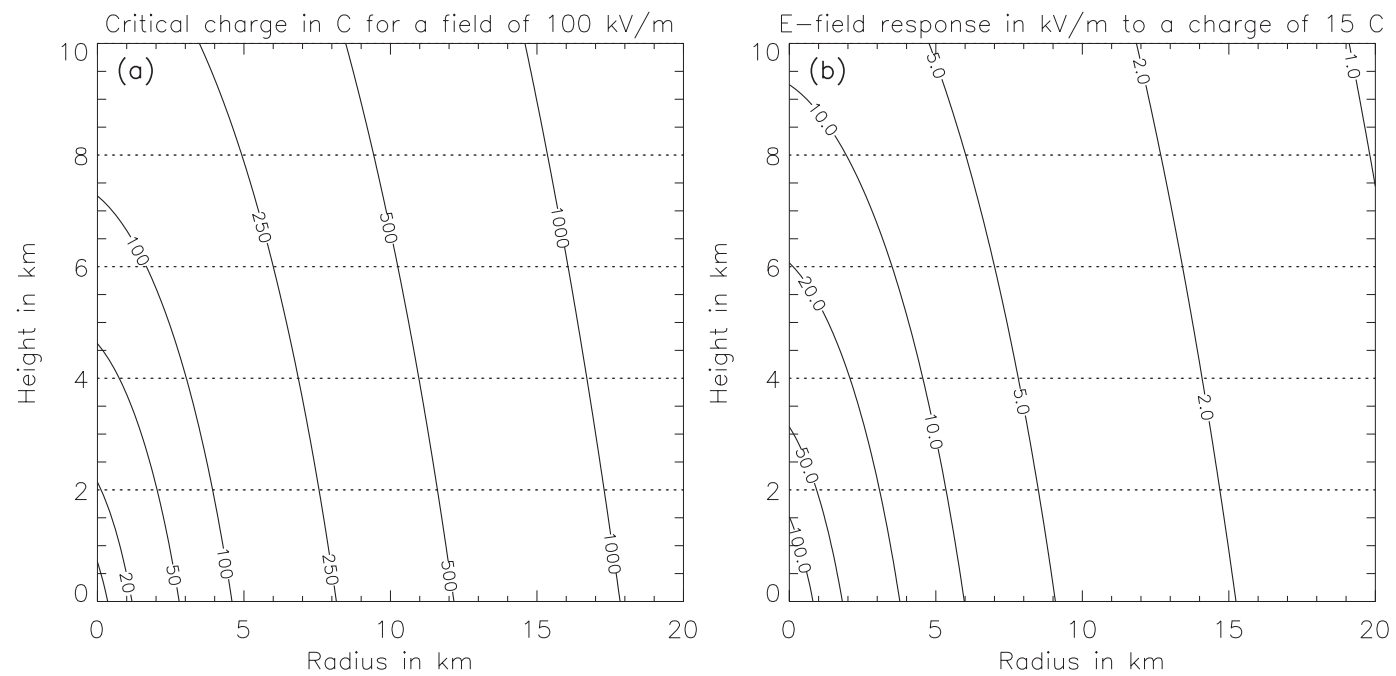

FIG. 2. The abscissa shows the plate radius and the ordinate the plate distance in $\mathrm{km}$. (a) Charge in $\mathrm{C}$ required to create an electric field strength of $100 \mathrm{kV} \mathrm{m}^{-1}$. (b) Response of the electric field in $\mathrm{kV} \mathrm{m}^{-1}$ to a charge of $15 \mathrm{C}$ for variable capacitor geometries.

capacitor plates will decrease as the radius increases (Fig. 2b). This implies that the larger the plates' geometry, the smaller the field-neutralization efficiency, and the higher the flash rate. Alternatively, per Eq. (10), we may consider $f=I / \Delta Q$. As the charging current is proportional to the plate area $(I=j A)$, the rate at which charge is replenished after a discharge increases with the plate area, and so does the flash rate. These explanations are consistent with each other and demonstrate conceptually how the different perspectives in Eq. (10) can be used to determine the lightning frequency.

The area dependence of the flash rate was also recognized by Larsen and Stansbury (1974) and is consistent with observations that the flash rates strongly depend on the sizes of the thunderstorms (Williams 2001). Thus far, it has been assumed that the only way to discharge the capacitor is through lightning. This is not necessarily realistic, since there are "leakage currents" due to corona discharges and precipitation charge (MacGorman and Rust 1998). This fact is accounted for by an additional factor $\gamma$, which is defined by the fraction

$$
\gamma=\frac{j_{l}}{j_{d}},
$$

where $j_{l}$ is the current density due to lightning and $j_{d}$ is the total discharging current density. ${ }^{7}$ Here, $\gamma$ will be referred to as lightning efficiency. Then, the flash-rate equation is given by

\footnotetext{
${ }^{7}$ This corresponds to the balance $I_{c}-I_{L}-I_{\text {leak }}=0$.
}

$$
f=\gamma j \frac{A}{\Delta Q}
$$

Next, we parameterize the variables in this equation in order to apply it to real-world thunderstorms.

\section{Parameterization of thunderstorm electricity}

The basic idea behind our description of thunderstorm electricity is a negatively charged graupel region in the lower and central portions of the storm and a positively charged ice region in the upper portions of the storm. Before describing the details of the parameterization, we briefly describe how lightning "flashes" are measured and defined.

\section{a. Lightning detection and definition of a "flash"}

To infer flash rates of observed storms, the lightning detection network, LINET, was used. LINET employs a time-of-arrival (TOA) technique based on signals measured in the very low-frequency/low-frequency (VLF/LF) band (Betz et al. 2004, 2009a,b). At these frequencies it is possible to cover large continental areas with a reasonable number of recording stations for real-time lightning detection (Betz et al. 2009a). Compared to other lightning location systems (LLSs), LINET offers a variety of advanced features such as (i) an optimized 2D location error as small as $150 \mathrm{~m}$, (ii) a new $3 \mathrm{D}$ discrimination technique for separating cloud-to-ground (CG) from intracloud (IC) events with good reliability, and (iii) the detection of much weaker lightning emissions compared to similar LLSs, thus having been used 
as a reference system (truth data) for cross-validation efforts.

A "lightning flash" is no single, well-defined phenomenon, but a complicated multistage discharge process, as detailed in, for example, Ogawa (1995) or Rakov and Uman (2003). This process involves electrical currents within multiple time and length scales. For the present purpose, a practical definition of a "discharge event" (i.e., a flash) is needed. Here, a flash includes all single VLF/LF signals (reported as a "stroke" by LINET, independent of lightning type) that occur within a distance of $10 \mathrm{~km}$ and within $1 \mathrm{~s}$ after the first stroke. Such grouping of strokes into a single flash event is a widely applied procedure [see the discussion by Shao et al. (2006), p. 7 and the references therein; McCaul et al. 2009], and it is used here mainly to render the predictions by the new approach comparable to other parameterizations.

\section{b. Estimating cloud-electricity parameters using observable cloud properties}

As described in the introduction, a possible approach to parameterizing the flash rate is to select an observable quantity (such as the rain rate) and use it as a lightningrate predictor. However, the goal of this study is to provide a physically consistent framework for predicting the lightning rate. The drawback of such a framework is that the predictor variables for the flash rate cannot be determined based on their observability. Rather, these are determined by the theoretical approach itself. This lack of freedom to select observable predictor variables is the price we pay for the physically consistent approach pursued herein. Although some information exists about the order of magnitude and the behavior of these variables, to our knowledge there exist no established relations between these predictor variables and observable cloud properties.

Our goal is thus to present estimates of such relations with the only purpose of rendering the theoretical framework applicable to real-world clouds. We do not intend to establish new and exact quantitative relationships between the predictor variables and observable cloud properties.

Altogether, the flash rate depends on four variables in our model:

$$
f=f(j, \Delta Q, \gamma, A)
$$

To apply this equation, a cumulonimbus cloud $(\mathrm{Cb})$ needs to be present or else bulk properties such as the cross-sectional area of the space charge regions (reflected by $A$; see below) cannot be defined meaningfully. As such, the approach is inherently object based (rather than being a gridpoint application). Herein, a $\mathrm{Cb}$ is defined as a region in space that contains a graupel-mass concentration $\geq 0.1 \mathrm{~g} \mathrm{~m}^{-3}$ above the $263-\mathrm{K}$ isotherm (henceforth referred to as the graupel region). This region is assumed to be negatively charged, consistent with the graupel-ice charging mechanism. Above this graupel region, an ice-mass concentration of at least $0.1 \mathrm{~g} \mathrm{~m}^{-3}$ needs to be present, which is assumed to contain positive charge. The temperature criterion was employed to consider only clouds that may contain negative and positive space charges and thus have the potential of producing lightning. The thresholds of $0.1 \mathrm{~g} \mathrm{~m}^{-3}$ were motivated by the application in a convection-permitting weather prediction model (Dahl et al. 2011, hereafter Part II). In that application, larger thresholds for the graupel and ice regions would have filtered out weak convective clouds, while too small a threshold would have resulted in too noisy fields. The choice of $0.1 \mathrm{~g} \mathrm{~m}^{-3}$ was a compromise between these extremes.

The plate area $A$ is described by the area of the horizontal cross section through the centroid position of the thunderstorm's main negatively charged (graupel) region.

\section{c. Method}

First, we identified two limiting "calibration" scenarios that represent two extreme forms of lightningproducing convection in central Europe. The desired estimates were found by refining formulations based on order-of-magnitude estimates and physical constraints until the lightning rates of the calibration scenarios were reproduced.

The "low end" scenario involves graupel showers in polar air. Many of these clouds do not produce lightning at all and, oftentimes, those that do, only produce one flash in their entire lifetime. For central Europe this type of thunderstorm arguably belongs to the weakest possible form of lightning-producing convection. Assuming that the convective time scale of an individual shower cell is of order $15 \mathrm{~min}$, the lightning rate in these weak thunderstorms is about one flash every $15 \mathrm{~min}$.

For the other end of the isolated-storm spectrum, we chose a day that resulted in severe and strongly flashing thunderstorms, including supercells, which produced as many as 60 flashes per minute. ${ }^{8}$

\footnotetext{
${ }^{8}$ Note that lightning rates of several hundred flashes per minute are reported to have accompanied intense supercells, as inferred from VHF sources using the Lightning Mapping Array (LMA) (e.g., Kuhlman et al. 2006). However, the LMA detects different properties of a discharge than LINET does, rendering the inferred flash rates not directly comparable. Moreover, grouping of VHF signals detected by the LMA into flashes is not straightforward and leads to uncertainties in the inferred flash rate especially in highflash-rate storms, as discussed in Wiens et al. (2005, p. 4157).
} 
These two scenarios were simulated with the German version of the Consortium for Small Scale Modeling model (COSMO-DE; Baldauf et al. 2011; Part II), and estimates of the cloud properties for the most intense (and some intermediate) cells on each day were obtained from the model and from radiosonde data. The maximum flash rates that occurred on these days were retrieved from LINET data. In this way, representative values for the two bounding extreme scenarios in terms of lightning rate and observable storm properties were obtained. It is worth emphasizing that no radar data were involved in this process and that none of the days presented in section 4 (and in Part II) were used to calibrate the parameterization.

The estimates based on these two scenarios provided a suitable range of independent variables for the parameterization functions. These variables are the space charge volume and the maximum graupel-mass concentration of the cell, which were chosen because of their relevance in cloud charging and discharging, as detailed below. The inferred charge volume ranges from about 3 to $300 \mathrm{~km}^{3}$ and the graupel-mass concentration ranges from about 0.1 to $3 \mathrm{~g} \mathrm{~m}^{-3}$. We used the maximum graupel-mass concentration of the cells, rather than the average because the latter did not exhibit as much variation between the calibration cases as the maximum values.

The two bounding calibration scenarios are summarized in Table 3. Although it is impossible to obtain highly accurate values with this method, we took them to be largely representative of the maximum graupel-mass concentration and of the geometry of the graupel region for each of the extreme cases.

Based on this information, a first-order formulation of the relationships between the variables and their parameters could be set up. We imposed three constraints on the desired relationships. These relationships needed to

- reproduce the flash rates of the calibration cases (requirement 1),

- be consistent with basic cloud-electrification and lightning physics (requirement 2), and

- have the correct orders of magnitude (requirement 3 ).

Fulfillment of requirement 1 was achieved by adjusting a first-guess formulation of the parameterization equations based on the information provided in the following
TABLE 3. Cloud properties and flash rates of the two extreme calibration scenarios.

\begin{tabular}{lcccc}
\hline \hline Scenario & Date & $\begin{array}{c}\text { Max } m_{g} \\
\left(\mathrm{~g} \mathrm{~m}^{-3}\right)\end{array}$ & $\begin{array}{c}\text { Charge } \\
\text { volume } \\
\left(\mathrm{km}^{3}\right)\end{array}$ & $\begin{array}{c}\text { Flash } \\
\text { rate } \\
\left(\mathrm{min}^{-1}\right)\end{array}$ \\
\hline Graupel shower & 3 Apr 2008 & 0.1 & 2.5 & $1 / 15$ \\
Supercell storm & 21 Jul 2007 & 3.0 & 300 & 60
\end{tabular}

paragraphs, until the flash rates of the calibration cases were reproduced. The outcome of these refinements is not unique in every detail, but we believe that the imposed constraints are stringent enough for our purposes. These constraints are detailed in the following.

\section{1) GENERATOR CURRENT DENSITY}

The generator-current density (see the appendix) is given by

$$
j=\rho v_{g},
$$

where $v_{g}$ is the average terminal fall speed of the graupel pellets. Within the context of a simple single-moment representation of graupel microphysics, the intercept parameter is constant and the slope parameter is determined by the graupel-mass concentration. This idea is adopted herein. Then, the number and the size of the graupel pellets tend to increase as the graupel-mass concentration increases. Because a larger number of graupel pellets implies a larger number of collisions (and charge transfer), the space charge density is assumed to increase as the graupel-mass concentration increases. As the size of the graupel pellets is correlated with their terminal fall speed, we assume the charge-flux velocity to increase as well, as the graupel-mass concentration becomes larger.

To describe the terminal fall velocity of graupel, representative sizes of graupel pellets are needed as input, which were taken from Pruppacher and Klett (1997, p. 58 ff.). In a first-order formulation, we assumed bounds of the graupel-diameter range of $1 \mathrm{~mm}$ and $1 \mathrm{~cm}$ for the weak and strong calibration scenario, respectively. After the refinement, the graupel diameter was found to vary between 2 and $12 \mathrm{~mm}$, so that the graupel diameter is parameterized as

$$
D_{g}\left(m_{g}\right)=\left\{\begin{array}{lll}
0.0 & \text { if } & 0.0 \leq m_{g}<0.1 \mathrm{~g} \mathrm{~m}^{-3} \\
1.833 \times 10^{-3}+3.333 \times 10^{-3} m_{g} & \text { if } & 0.1 \leq m_{g} \leq 3.0 \mathrm{~g} \mathrm{~m}^{-3} \\
0.012 & \text { if } & m_{g}>3.0 \mathrm{~g} \mathrm{~m}^{-3}
\end{array}\right.
$$


where $D_{g}$ is the graupel diameter in $\mathrm{m}$ and $m_{g}$ is the maximum graupel-mass concentration in the given thunderstorm cell. ${ }^{9}$

The terminal velocity of the graupel pellets is given by an empirical formula due to Heymsfield and Kajikawa (1987):

$$
v_{g}=422.0 D_{g}^{0.89}
$$

where $v_{g}$ is given in meters per second and $D_{g}$ is is given in meters. Accordingly, the charge-flux velocity ranges from about 2 to $8 \mathrm{~m} \mathrm{~s}^{-1}$, increasing with the graupelmass concentration.

An order-of-magnitude estimate of the space charge density in the generator current is $\rho=\mathcal{O}\left(10^{-9}\right) \mathrm{C} \mathrm{m}^{-3}$ (e.g., MacGorman et al. 2001). Also, the above reasoning suggests that it increases as the graupel-mass concentration increases. We have assumed a linear increase of $\rho$ within the prescribed range [Eq. (32)]. This behavior was retained after the refinement, with $\rho$ varying between 0.7 and $9.8 \mathrm{nC}$. The functional relationship is thus

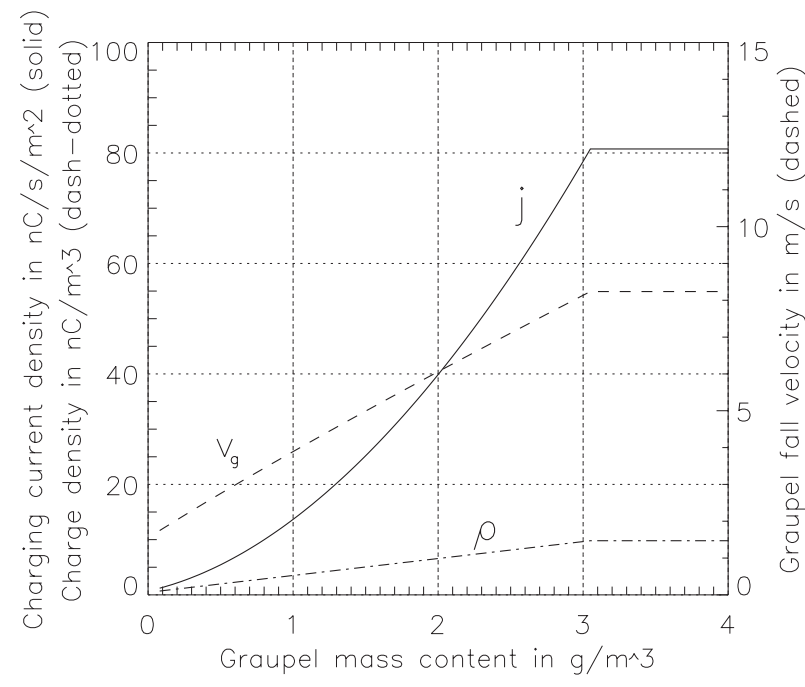

FIG. 3. Parameterizations based on the graupel-mass concentration. The dashed line represents the terminal fall velocity of the graupel in $\mathrm{m} \mathrm{s}^{-1}$ (right scale), the dashed-dotted line represents the charge density in the generator current in $\mathrm{nC} \mathrm{m}^{-3}$, and the solid line represents the resulting generator current density in $\mathrm{nC} \mathrm{s}^{-1} \mathrm{~m}^{-2}$.

$$
\rho=\left\{\begin{array}{lll}
0.0 & \text { if } & 0.0 \leq m_{g}<0.1 \mathrm{~g} \mathrm{~m}^{-3} \\
4.467 \times 10^{-10}+3.067 \times 10^{-9} m_{g} & \text { if } & 0.1 \leq m_{g} \leq 3 \mathrm{~g} \mathrm{~m}^{-3} \\
9.8 \times 10^{-9} & \text { if } & m_{g}>3 \mathrm{~g} \mathrm{~m}^{-3}
\end{array}\right.
$$

where $\rho$ is the space charge density in the generator current (given in $\mathrm{C} \mathrm{m}^{-3}$ ). These parameterizations are shown in Fig. 3.

\section{2) LightNing CHARGE}

The question of how much charge is depleted during breakdown given a finite space charge region led to laboratory experiments (Cooke et al. 1982; Williams et al. 1985) and theoretical considerations (Phelps 1974).

\footnotetext{
${ }^{9}$ Based on Eq. (31) it is not obvious how the coefficients are related to the bounds of the dependent variables. The parameterizations were formulated in a lookup-table style: The range of independent (parameter) variables ( such as $m_{g}$, Table 3 ) was written as

$$
m_{g}(i)=0.05+0.03 i \quad \text { where } \quad i=1, \ldots, 100,
$$

and the refined dependent (parameterized) values such as $D_{g}$ were written as

$$
D_{g}(i)=0.002+0.0001 i \quad \text { where } \quad i=1, \ldots, 100 .
$$

Solving Eq. (32) for $i$ and inserting it in Eq. (33) yields the functional form, Eq. (31). This form is more compact than the lookuptable style and will also be used for the other relationships.
}

The basic result is that the more extensive the channel system, the more charge is depleted. According to these experiments, the channel-propagation depth is determined by the space charge density [which was also confirmed with numerical experiments; see Mansell et al. (2002)] and by the size of the charge region (Cooke et al. 1982). For simplicity, it is assumed herein that the critical charge density does not vary much with storm geometry and, hence, that the lightning charge only depends on the size of the charge regions. The dependence of channel length on storm size was also suggested by Huntrieser et al. (2008).

Consequently, the charge volume is used to parameterize the lightning charge. To determine this volume, the horizontal cross-sectional area of the graupel region at its centroid position is multiplied by the average thickness of the graupel and ice regions. In applying this definition (next section and Part II), this thickness is determined by the vertical extent of these regions at the centroid location of the graupel zone.

The implication of the preceding analysis is that the lightning charge increases as the charge volume increases. 


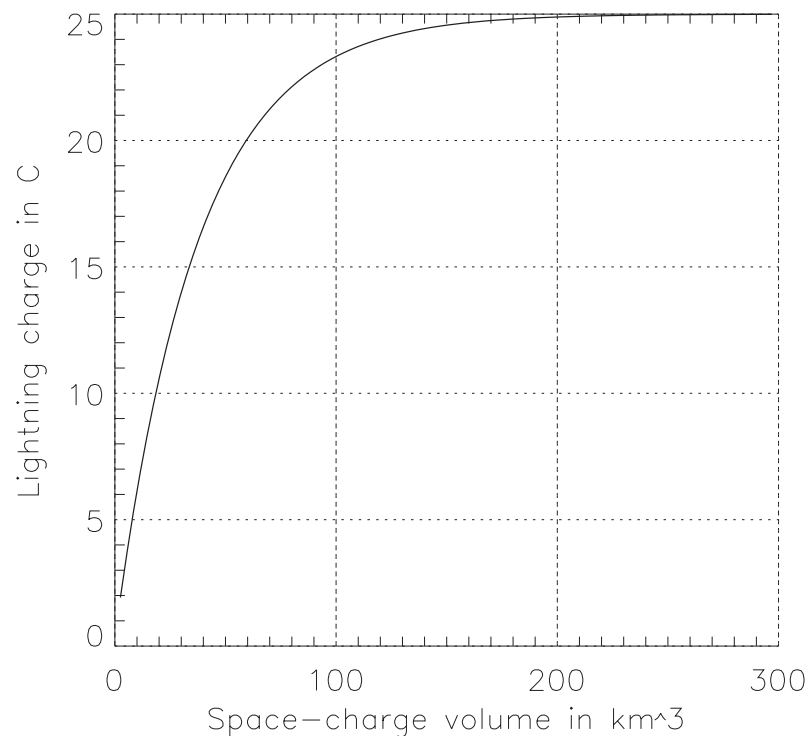

FIG. 4. Charge in $\mathrm{C}$ deposited in a flash as a function of the volume of the space charge region.

An order-of-magnitude estimate for reasonable values of the lightning charge was taken from Maggio et al. (2009), who report average charge magnitudes of about $18 \mathrm{C}$ (IC discharges), and $9 \mathrm{C}$ (CG discharges), although
TABLE 4. Summary of parameterized variables and their parameters.

\begin{tabular}{ll}
\hline \hline \multicolumn{1}{c}{ Variable } & \multicolumn{1}{c}{ Parameterization } \\
\hline Space charge area $A$ & Graupel-mass concentration \\
Lightning efficiency $\gamma$ & Set to constant value \\
Space charge volume $V$ & Graupel- and ice-mass \\
& concentration \\
Lightning charge $\Delta Q$ & Graupel- and ice-mass fields \\
& (space charge volume) \\
Generator charge & Graupel-mass field \\
density $\rho_{c}$ & Graupel-mass field (terminal \\
Generator charge & graupel fall velocity) \\
velocity $v_{g}$ &
\end{tabular}

they found substantial variations in the thunderstorms they investigated.

To keep the charge density in the generator current and the graupel velocity within reasonable bounds, the maximum lightning charge was required to remain below $25 \mathrm{C}$ to reproduce the flash rates of the calibration cases (requirement 1). The steep increase of the lightning charge with small volumes was employed to capture intermediate cases.

Then, the lightning charge $\Delta Q$ expressed as a function of the mean volume of the two charge regions $V$ can be approximated by

$$
\Delta Q=\left\{\begin{array}{ll}
0.0 & \text { if } \quad 0.0 \leq V<2.5 \mathrm{~km}^{3} \\
25[1-\exp (-0.013-0.027 V)] & \text { if } \quad V \geq 2.5 \mathrm{~km}^{3}
\end{array},\right.
$$

where $\Delta Q$ is given in $\mathrm{C}$ and the volume is given in $\mathrm{km}^{3}$. Again, the coefficients result from prescribing an increase of lightning charge that saturates at $25 \mathrm{C}$ across the range of the charge volume (Table 3 ) and then formulating the relation as a function of $V$. This relation reflects an increase of lightning charge from about 2 to about $25 \mathrm{C}$ as the charge volume increases. Figure 4 provides a graphical summary of this relationship.

\section{3) LIGHTNING EFFICIENCY}

The lightning efficiency describes the contribution from lightning to the total discharging of the capacitor. Aside from lightning, conduction currents into the electrosphere, corona currents, and precipitation currents are known to discharge the cloud (these contributions may be considered to be leakage currents; see also Fig. 1). To our knowledge, no well-established quantitative estimates exist with respect to the magnitude of these contributions [see, however, MacGorman and Rust (1998), p. 53 ff. for an overview]. A simple solution would have been to set the lightning efficiency to unity (i.e., to neglect it). But since we sought to retain this factor, and know that it is smaller than one, we set it to 0.9. Table 4 summarizes the variables and their parameters.

\section{Test of the approach}

In this section, the approach developed herein (henceforth abbreviated DHS11) is tested against lightning observations, using radar data to estimate the microphysics parameters. The results will be interpreted and discussed in the next section.

To test the approach, radar measurements were used to determine the storm parameters that are required as input to the flash-rate equation. The measurements were obtained from a polarization-diversity radar [the Deutsches Zentrum für Luft- und Raumfahrt e.V. (DLR, the German Aerospace Agency) polarimetric radar (POLDIRAD); Schroth et al. (1988)]. This radar operates in the $\mathrm{C}$ band and is located in southern Germany at the DLR facility in Oberpfaffenhofen, roughly $25 \mathrm{~km}$ southwest of Munich. With its polarimetric capabilities the shape of the hydrometeors may be inferred, which in turn may be associated with certain 
hydrometeor classes (Höller et al. 1994). Empirical relations are used to infer the hydrometeor mass concentrations from the radar reflectivity values (Höller 1995; Fehr et al. 2005). The geometry of the graupel regions and the maximum graupel-mass concentration were assessed using constant-altitude plan-position indicator (CAPPI) and range-height indicator (RHI) products. To compare the flash-rate predictions with observations, LINET data were used.

As an example, Fig. 5 shows a vertical cross section through an intense hailstorm that occurred over southern Germany on the afternoon of 22 August 2008. Shown are the graupel-mass concentration (Fig. 5a) and the snow-mass concentration (Fig. 5b). The 263-K isotherm was found to be at an altitude of about $5.5 \mathrm{~km}$, based on the 1200 UTC sounding from MünchenOberschleissheim (not shown). As shown in Fig. 5a, the centroid height of the graupel region was estimated to be at an altitude of about $8 \mathrm{~km}$. The diameter of the graupel region at this altitude is about $17 \mathrm{~km}$ with a depth of about $6 \mathrm{~km}$. CAPPI data (not shown) were used to refine the inferred diameter in case the graupel area was substantially noncircular. The ice region above the graupel region (Fig. 5b), which in our approach is assumed to contain the positive space charge, has a depth of about $2 \mathrm{~km}$. The average depth of the charged graupel and ice regions is thus about $4 \mathrm{~km}$. These values are summarized in Table 5. The hail category (not shown) was included in the graupel-mass concentration because one application of the lightning parameterization will be its implementation in a mesoscale numerical weather prediction model, where there is no separate hail category (Doms and Schättler 2002; Baldauf et al. 2011). Because in our approach the generator-current density is constant for graupel-mass concentration larger than $3 \mathrm{~g} \mathrm{~m}^{-3}$, this inclusion of hail does not affect the results.

Using these measurements as well as the estimates presented in the previous section, and inserting this information into Eq. (28), we find that the predicted flash rate $f_{p}=40 \mathrm{~min}^{-1}$.

Although several series of retrieving the data were performed that reproduced the result, we considered a rather generous error of $\pm 5 \mathrm{~km}$ in determining the diameter to account for the nonautomated nature of the data-retrieval technique. We assumed this error for all investigated storms. Only in cases where the plate diameter was substantially less than $5 \mathrm{~km}$ was an error of $\pm 1 \mathrm{~km}$ used. ${ }^{10}$

\footnotetext{
${ }^{10}$ A mouse-over function of the software used to display the radar data resulted in a higher accuracy in retrieving the data than is implied by the images in Fig. 5.
}

If in the above example the graupel region's diameter is allowed to vary by $\pm 5 \mathrm{~km}$, the predicted flash rate ranges from 20 to $66 \mathrm{~min}^{-1}$.

The comparison with LINET flashes was realized as follows. As the time of the radar scan was known, plots of observed flashes densities (flashes per area) were produced. These included all flashes in three time intervals $(5,10$, and $15 \mathrm{~min})$ centered around the time of the scan. The reason for considering three intervals is that the instantaneous flash rate may tend to fluctuate, and a value that represents the electric activity in the current stage of the cell was sought. The coherent flash-density regions were identified using a clusteridentification algorithm (Part II), and the total number of flashes contributing to each region was counted. Since the time interval was known, the mean flash rate per "lightning cell" could be determined, and it could easily be associated with the position of the radar echo. In the above example, the average measured flash rate was $f_{L}=33 \mathrm{~min}^{-1}$. The flash rates in the three time intervals ranged from 27 to $38 \mathrm{~min}^{-1}$.

The procedure described above was repeated for several cells that occurred on various days and in different synoptic regimes. The following technical criteria were used in choosing these cases:

- the cells were required to be in reasonably close proximity to the radar, so that the measurement quality was high and

- the entire cell or the entire segment of a squall line needed to be covered by the scans.

Another criterion included the structure and intensity of the storms. These conditions were supposed to include at least the following "types" of convection:

- shallow, weakly flashing polar-air convection;

- isolated, poorly organized, and weak thunderstorms;

- elevated thunderstorms;

- isolated, severe supercells;

- squall lines/bow echoes; and

- well-organized mesoscale convective systems (MCSs), containing supercells.

This selection largely comprises the range of convective storms that may occur over central Europe, and it contains extremes on both the weak and the strong ends, as well as rather common scenarios.

Whenever attenuation effects occurred, which could not be accounted for (e.g., by using other scans), the case was excluded from further analysis.

Table 6 shows some details about the investigated cases, as well as the (averaged) observed and predicted flash rates. The times of the individual scans were determined by the proximities of the storms to the radar 
a)

22 Aug 2008 15:37 RHI 100.0 deg

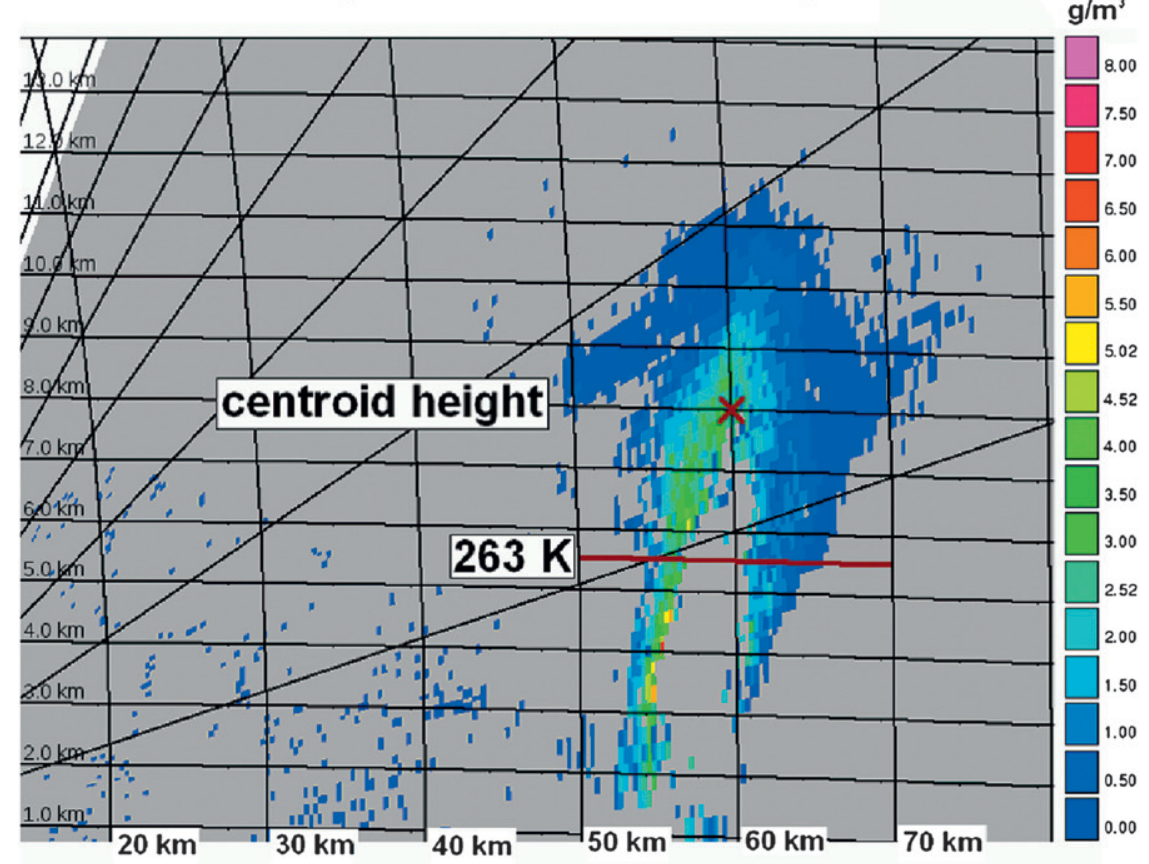

b)

\section{Aug 2008 15:37 RHI 100.0 deg}

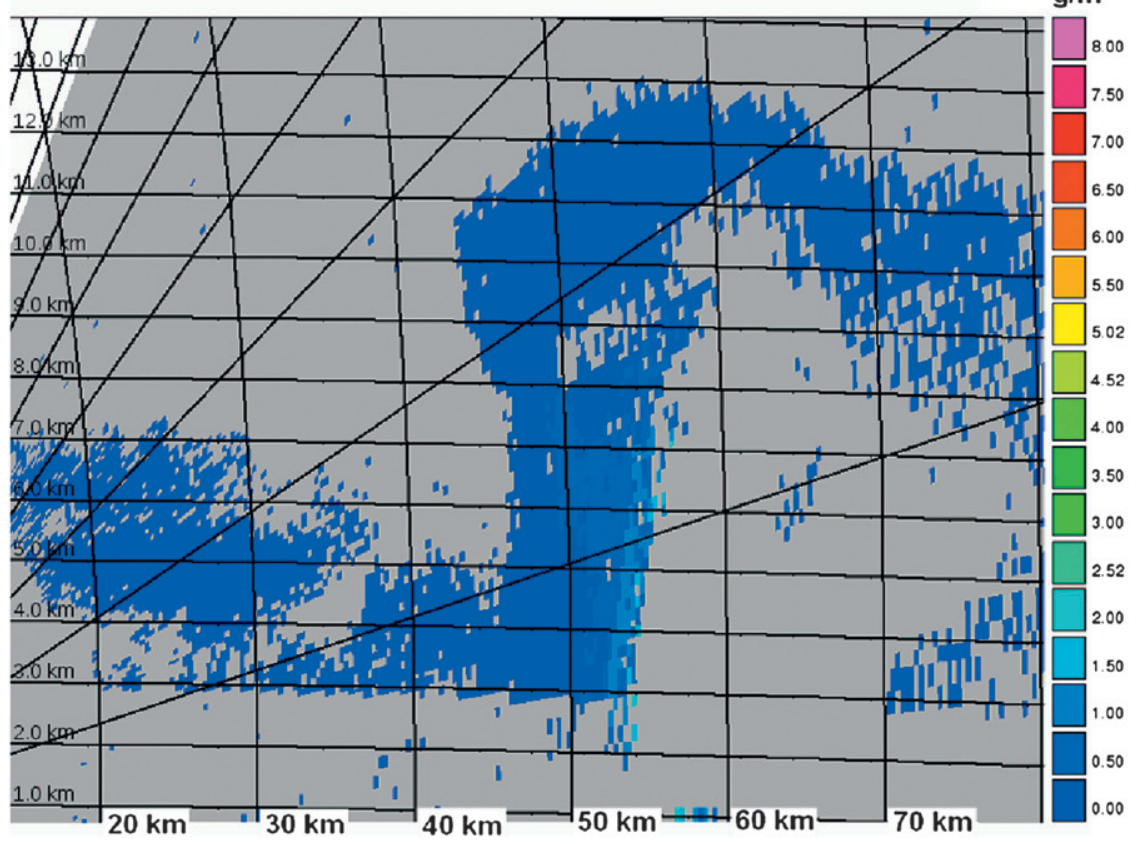

FIG. 5. POLDIRAD RHI display of a severe hailstorm at 1537 UTC 22 Aug 2008. (a) The graupel-mass and (b) snow-mass concentrations in $\mathrm{g} \mathrm{m}^{-3}$. The dark-red line in (a) depicts the height of the $263-\mathrm{K}$ isotherm and the crisscross shows the approximate location of the centroid location of the graupel region. The abscissa and ordinate show the horizontal and vertical distances from POLDIRAD in $\mathrm{km}$, respectively. 
TABLE 5. Parameters and their values as inferred from the POLDIRAD radar data at 1537 UTC 22 Aug 2008. The height of the $263-\mathrm{K}$ isotherm was retrieved from the 1200 UTC radiosonde ascent from München-Oberschleissheim. The graupel-mass concentration includes the hail category.

\begin{tabular}{ll}
\hline \hline \multicolumn{1}{c}{ Variable } & \multicolumn{1}{c}{ Value } \\
\hline Max graupel-mass concentration & $8.0 \mathrm{~g} \mathrm{~m}^{-3}$ \\
Plate thickness & $4.0 \mathrm{~km}$ \\
Plate diameter & $17 \pm 5 \mathrm{~km}$ \\
Charge area & $227 \mathrm{~km}^{3}$ \\
Charge volume & $900 \mathrm{~km}^{3}$ \\
263-K isotherm height & $5.5 \mathrm{~km} \mathrm{MSL}$ \\
Height of graupel centroid position & $8 \mathrm{~km} \mathrm{MSL}$ \\
\hline
\end{tabular}

and the quality of the scans. There is one complete miss on 26 June 2009, where weakly flashing storms were observed, but no graupel was found above the $263-\mathrm{K}$ level. As a consequence, application of the parameterization yielded zero flashes per minute. A case where precipitating moist convection but no lightning occurred has also been included (zero-lightning graupel shower on 23 January 2009), which was correctly handled by the parameterization.

A scatter diagram of the results shown in Table 6 is presented in Fig. 6. The error bars reflect the uncertainty in the cell diameter. The response of the flash rate to the error is nonlinear and generally increases with increasing flash rate. This plot is dominated by three data points belonging to MCS cases with flash rates in excess of $100 \mathrm{~min}^{-1}$. When omitting these cases and considering only the 11 remaining data points (non-MCS cases), these are closely aligned along a linear fit; see Fig. 7. The slope of this fit, $b=0.91$ [0.48, 1.48] (the values in brackets refer to the bottom and top ends of the error-bar values, respectively) and the correlation coefficient is 0.98 [0.97, 0.96]. The
RMSE $=4.2[2.4,8.6] \mathrm{min}^{-1}$, and the mean absolute error is $3.2[2.0,6.03] \mathrm{min}^{-1}$.

\section{Discussion}

We have provided a simple but physically consistent theoretical model, which we have rendered applicable to real-world thunderstorms using estimates of how observable cloud features relate to electrical properties of the cloud. In this section, we would like to address some limitations and implications of this approach.

\section{a. Theoretical part}

An obvious simplification is that the model features only two charge regions. Although it is well known that the details of the charge distribution especially in organized storms is quite complex, including multiple charge layers as well as small pockets of charge (e.g., Stolzenburg et al. 1998; Kuhlman et al. 2006), the overall charge structure of some of these storms may still be as simple as a tripole (Kuhlman et al. 2006, their Fig. 17).

Moreover, we only considered the total flash frequency in this study, which arguably is the coarsest possible description of a thunderstorm's lightning activity. More refined descriptions would involve a distinction between IC and CG discharges and the polarity of the discharges.

To predict the CG lightning rate, the lower positive charge region probably needs to be included (Stolzenburg and Marshall 2009), as does the subcloud field due to the storm's image charge. The neglect of CG discharges is inherent to all approaches that are based on two in-cloud charge regions (e.g., Price and Rind 1992; Yoshida et al. 2009). Also, the polarity of the discharges is not predicted in the current model. Clearly, higher-order descriptions than a dipole would be required to include these details. Moreover, the DHS11 approach does not handle MCSs

TABLE 6. Summary of cases used for testing the flash-rate equation. See text for details. WAA is short for warm-air advection, $f_{p}$ is the predicted flash rate, and $f_{L}$ is the mean of the 5-, 10-, and 15-min averages of measured flash rates. Here, $f_{p}$ range is the frequency variation based on diameter errors.

\begin{tabular}{|c|c|c|c|c|}
\hline Date & Scenario & $f_{p}\left(\min ^{-1}\right)$ & $f_{L}\left(\min ^{-1}\right)$ & $f_{p}$ range \\
\hline 23 Jun 2008 & Isolated supercell & 26 & 21 & {$[11,49]$} \\
\hline 24 Jun 2008 & WAA regime, weak, elevated & 1.5 & 1.5 & {$[1.1,1.9]$} \\
\hline $20 \mathrm{Jul} 2008$ & Shallow but sheared & 0.17 & 0.93 & {$[0.12,0.20]$} \\
\hline 22 Aug 2008 & Isolated supercell & 40 & 33 & {$[20,66]$} \\
\hline 23 Jan 2009 & Shallow snow/graupel showers & 0.0 & 0.0 & {$[0.0,0.0]$} \\
\hline 26 May 2009 & Approaching squall line & 493 & 212 & {$[414,579]$} \\
\hline 26 May 2009 & Departing squall line & 527 & 217 & {$[445,615]$} \\
\hline 26 Jun 2009 & Single cell & 0.0 & 0.5 & {$[0.0,0.0]$} \\
\hline 30 Jun 2009 & Single cell & 8.5 & 2.8 & {$[6.9,10.3]$} \\
\hline 30 Jun 2009 & Weak multicell & 7.5 & 5.0 & {$[6.8,8.7]$} \\
\hline 5 Jul 2009 & Single cell & 0.6 & 0.5 & {$[0.5,0.6]$} \\
\hline 5 Jul 2009 & Weak multicell & 10 & 9.2 & {$[8.4,11.7]$} \\
\hline $23 \mathrm{Jul} 2009$ & Isolated supercell & 55 & 64 & {$[31,87]$} \\
\hline $23 \mathrm{Jul} 2009$ & Severe MCS & 242 & 106 & {$[188,303]$} \\
\hline
\end{tabular}




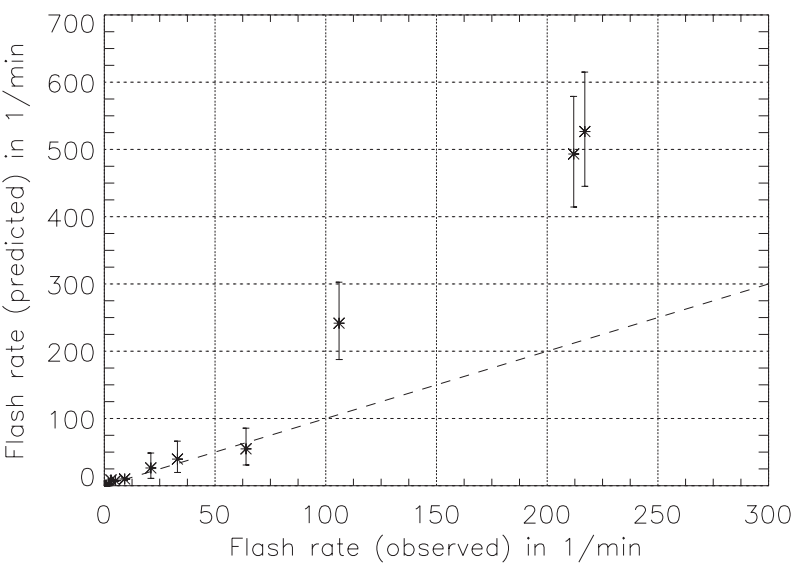

FIG. 6. Scatterplot showing observed ( $x$ axis) and predicted ( $y$ axis) flash rates based on the DHS11 approach. Also shown is the line representing perfect correlation $(r=1, b=1)$.

as accurately as discrete storms, which may reflect the fact that the dipole approximation breaks down as the storm structure becomes increasingly complex.

Another limitation of the DHS11 approach is its artificially prescribed balance, implying that the critical field strength is maintained exactly by the generator current against discharges. This restriction may become important when the storm geometry and the graupel content are strongly time dependent, as might happen during the early stages of the developing thunderstorm.

\section{b. Parameterizations}

The parameterization formulas have the sole purpose of providing an estimate of the predictors in the flashrate equation, rather than establishing new and exact relationships (e.g., between the graupel-mass concentration and the space charge density in the generator current). For such purpose, the selected method would have been too crude. Although the imposed constraints ensure that these relationships are physically meaningful and have the correct orders of magnitude, they were not individually tested given a lack of observations of these relationships. In concert, the parameterizations yield accurate predictions at least for the discrete storms we tested, but we do not claim that these formulations are unique.

Like Price and Rind (1992) and Yoshida et al. (2009), we calibrated the parameterizations based on the total flash rate, although strictly speaking, the two-plate model only includes IC lightning, which may lead to minor inconsistencies. Moreover, the new parameterization has a somewhat undesirable property resulting from the rigid top and bottom bounds that are based on the two "limiting" calibration cases. A consequence is that the lightning rate for storms with graupel-mass

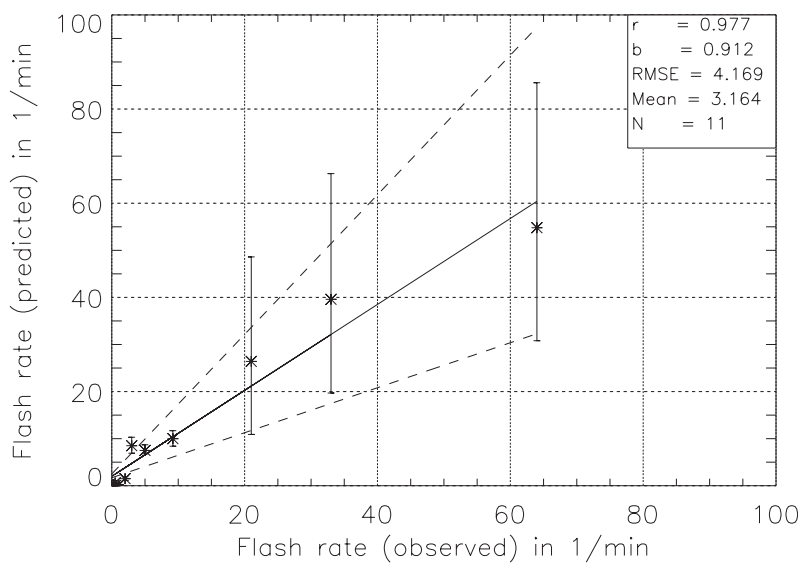

FIG. 7. As in Fig. 6, but omitting the three MCS cases. In the inset, the correlation coefficient $r$, the slope of the regression line $b$, as well as the RMSE, the mean error, and the number of data points $N$, are shown. The dashed lines show the linear fits pertaining to the extreme ends of the error bars (see text).

concentrations and charge volumes above these bounds (such as the example of 22 August 2008) is solely determined by the horizontal extent of the graupel region. It is not clear whether this is a realistic property of the parameterization. However, it may imply that for such storms the effects of the large generator-current density (favoring high lightning rates) is offset by the effects of large lightning charge (favoring low lightning rates). Physically, an upper limit of the graupel-mass concentration may be set by the occurrence of wet growth.

Ultimately, the need to resort to somewhat coarse representations of the electrical cloud properties is a result of adopting a theoretically consistent approach. This approach dictates which parameters are required to obtain the lightning rate, without taking into consideration whether or not these parameters are amenable to observations. Since the goal of this study is to demonstrate the applicability of a simple and yet physically consistent approach, this compromise was deemed to be acceptable.

The DHS11 approach is designed for application to a convective-cell entity, which implies that $m_{g} \geq 0.1 \mathrm{~g} \mathrm{~m}^{-3}$ and $m_{i} \geq 0.1 \mathrm{~g} \mathrm{~m}^{-3}$. If applied to an arbitrary point in space and time (within or outside of a convective cell), quantities such as the charge volume or the cell's horizontal area become ill-defined. Moreover, physical consistency is no longer guaranteed in this case, as the expressions for the generator-current density and lightning charge include constant offsets, suggesting nontrivial charging and discharging even if $m_{g}=0 \mathrm{~g} \mathrm{~m}^{-3}$. The fact that these parameterizations are applicable only to bulk properties of the cell is consistent with a convective cell having only one flash rate at a given time (rather than an infinite number of flash rates for every point in space within the cell). 


\section{c. Limits of the parameterization}

In large MCSs, charge-moment changes of $1500 \mathrm{C} \mathrm{km}^{-1}$ were observed $^{11}$ ( $\mathrm{Lu}$ et al. 2009), which is beyond the bound of $25 \mathrm{C}$. Although the overestimation of the lightning rate of the observed three MCSs may be reduced by increasing the lightning charge, we doubt that the DHS11 approach is capable of handling MCSs properly given the complex charge structures of these systems.

The simplifying assumptions regarding the charge structure also affect shallow storms. To treat a convective cell as a potential thunderstorm, the graupel region is required to extend above the $263-\mathrm{K}$ level. Otherwise, the cell is not considered to produce flashes. Although only one case was observed where this criterion discarded a cell that was observed to produce lightning, it shows that the simplified approach breaks down in some very marginal situations.

\section{d. Other approaches}

The parameterizations put forth by Yoshida et al. (2009) and Price and Rind (1992) were also tested, but quantitative comparisons among the different parameterizations and with LINET data are not presented for the following reasons. The parameterization by Price and Rind (1992) is based on results by Williams (1985), who used data from the 1950s-70s (Shackford 1960; Jacobson and Krider 1976), which were partly based on visual observations and on broadcast TV records. The detection efficiency of these methods is not known. Price and Rind (1992) used a satellite-based optical sensor to verify their approach, but the detection efficiency of this sensor is uncertain, as well. Regarding the approach by Yoshida et al. (2009), there are uncertainties about the comparability of LINET and Lightning Imaging Sensor (LIS; Finke 2009) data, as well as about the applicability of their parameterization to central European storms. Qualitatively, the approaches of Price and Rind (1992) and Yoshida et al. (2009) cannot be expected to reproduce the observed variability between the individual storms because the (cold) cloud depths are determined mainly by the thermodynamic environment. Storm organization and intensity, on the other hand, are strongly dependent on the vertical wind shear in the storms' environment (e.g., Johns and Doswell 1992). Hence, the (cold) cloud depths do not necessarily vary between the different storm structures (e.g., the weakly flashing and weakly organized storms on 30 June 2009 and the strongly flashing supercell on 22 August 2008 had the

\footnotetext{
${ }^{11}$ If charge is removed from altitudes of order $10 \mathrm{~km}$, this corresponds to about $150 \mathrm{C}$ of lightning charge.
}

same cloud-top height of about $13 \mathrm{~km}$; not shown). When using these parameterizations, it thus must be kept in mind that they are designed for application on the global scale, where such variations are averaged out.

The DHS11 approach does not predict an increase in the lightning rate with cloud depth, which seems to be inconsistent with many observations that do suggest such an increase (e.g., Williams 1985; Price and Rind 1992; Yoshida et al. 2009). We speculate that this cloud-height dependence might be an indirect effect. Dynamic entrainment tends to increase with updraft velocity (Houze 1993, p. 257), which implies that skinny and strong updrafts may not as easily be sustained against entrainment as wide and strong updrafts. If in addition strong updrafts are deeper than weak updrafts, as suggested by, for example, Yoshida et al. (2009), then it may be inferred that the cloud-top height indeed increases with the cloud width (although this relationship may not necessarily be linear). An additional factor is that the amount of supercooled liquid water, which is required for graupel growth, increases with updraft speed (Zipser 1994), resulting in a strengthening generator-current density as the updraft becomes more intense (and deeper). These contributions may indirectly result in a nonlinear dependence of the lightning rate on the cloud-top height.

\section{Summary}

In this work a straightforward theoretical approach was combined with estimates that relate cloud electricity to observable cloud properties, to describe the total lightning rate of a thunderstorm (no distinction is made between CG and IC lightning). Lightning is described as discharges between two oppositely charged capacitor plates. The main idea behind this model is that the discharge frequency not only depends on the charging rate of the capacitor, but also on the strength of the discharges. In this approach, negative charge is associated with graupel and positive charge with ice particles. The geometry of the capacitor plates is inferred from the graupel- and ice-mass concentrations.

It was shown that the flash rate can be determined if the generator current density, the cross-sectional area of the graupel region, the lightning efficiency (i.e., the degree to which the lightning current contributes to the overall discharging process), as well as the lightning charge are known. The generator current density is parameterized using the maximum graupel-mass concentration above the $263-\mathrm{K}$ isotherm and the lightning charge is parameterized using the volume of the space charge regions. Altogether, only information about the graupel- and ice-mass concentrations is required to determine the flash rate. 
Overall, the qualitative prediction of this approach is that thunderstorm cells with a small horizontal extent and a weak graupel-mass concentration exhibit small flash rates, while horizontally extensive cells with large graupel-mass concentrations exhibit high flash rates.

To test these predictions, the new framework was applied to measurements from a polarimetric radar and from radiosondes. The resulting predictions were compared with measurements from the LINET lightning detection network.

For discrete (non-MCS) thunderstorms the results using the DHS11 approach are encouraging: the correlation coefficient between observed and predicted flash rates exceeds 0.9 with an RMSE of about four flashes per minute. The flash rates of the thunderstorms used for this test varied from one flash every few minutes to about one flash per second. If MCS cases are considered, the DHS11 approach results in an overestimation of the flash rate by a factor of about 2 .

The long-standing question of whether the flash rate is proportional to the generator power or generator current is answered with "neither." In general, any quantity uniquely describing a breakdown criterion, like the critical electrostatic energy, the critical charge, or the critical electric field, may be chosen; then, the flash rate is given by the ratio of the temporal rate of increase of this quantity and its dissipation during a discharge. The latter factor is ignored when employing linear proportionalities between the charging rate (expressed either as generator power or generator current) and the flash rate. If other discharging mechanisms than lightning are admitted in the model, then an additional factor, the "lightning efficiency," may be included. The new concept is consistent with a strong dependence of the lightning rate on the storm size.

Acknowledgments. We thank Drs. George Craig and Christian Keil for their support during the course of the work. Helpful discussions about cloud electrification and lightning with Drs. Ted Mansell, Dennis Boccippio, Axel Seifert, Kersten Schmidt, Earle Williams, and Rohan Jayaratne are gratefully acknowledged. Professor H. D. Betz kindly provided the LINET data. Our thanks are extended to the Convective Storms Group at NCSU and to the anonymous reviewers for their careful comments on the manuscript. This study was funded by the DLR project "Wetter und Fliegen."

\section{APPENDIX}

\section{The Generator Current Density}

The number $N_{k}$ of hydrometeors of class $k$ per unit volume is given by

$$
N_{k}=\int_{0}^{\infty} f_{k}(D) d D
$$

where $f_{k}(D)$ is the particle-size distribution and $D$ is the diameter of the particles. To obtain the total charge per unit volume due to particles of class $k$, we may write

$$
\rho_{k}=\int_{0}^{\infty} \bar{\rho}_{k}(D) d D
$$

where $\bar{\rho}_{k}(D)=\bar{q}_{k}(D) f_{k}(D)$ is the spectral charge density and $\bar{q}_{k}(D)$ is the average charge per $k$ particle in the diameter range $d D$.

To obtain the current density $j_{k}$, the sedimentation velocity of the hydrometeors needs to be included:

$$
j_{k}=-\int_{0}^{\infty} v_{k}(D) \bar{\rho}_{k}(D) d D,
$$

where $v_{k}(D)$ is the average magnitude of the terminal fall velocity of particles of class $k$ and diameter $D$. The negative sign appears because the hydrometeors are falling downward (at the moment, it is assumed that there are no vertical motions of the ambient air). If the net effect of all hydrometeor classes is included, then

$$
j=-\sum_{k} \int_{0}^{\infty} v_{k}(D) \bar{\rho}_{k}(D) d D .
$$

This result corresponds to the findings of Boccippio (2002, p. 1096). Now only two classes shall be considered: ice crystals and graupel. Moreover, the average diameter $\bar{D}_{k}$ of the hydrometeors in each class is used and modeled by a delta distribution. We let $\tilde{q}_{k}$ represent the average charge carried on all the particles of class $k$, so that

$$
\bar{\rho}_{k}(D)=\bar{q}_{k}(D) f_{k}(D)=\tilde{q}_{k} N_{k} \delta\left(D-\bar{D}_{k}\right) .
$$

If the suffixes $g$ and $i$ pertain to graupel pellets and ice crystals, respectively, Eq. (A4) may be written as

$$
\begin{aligned}
j= & -\int_{0}^{\infty} v_{g}(D) \tilde{q}_{g} N_{g} \delta\left(D-\bar{D}_{g}\right) d D \\
& -\int_{0}^{\infty} v_{i}(D) \tilde{q}_{i} N_{i} \delta\left(D-\bar{D}_{i}\right) d D .
\end{aligned}
$$

Assuming that charge is conserved, we may write

$$
N_{i} \tilde{q}_{i}=-N_{g} \tilde{q}_{g} \quad \text { or } \quad \rho_{i}=-\rho_{g},
$$

and define the magnitude of the total charge density due to each class as 


$$
\rho=\left|\rho_{g}\right|=\left|\rho_{i}\right|
$$

Then, noting that $\rho_{g}<0$, we may write Eq. (A6) as

$$
j=-\rho_{g} v_{g}-\rho_{i} v_{i}=\rho\left(v_{g}-v_{i}\right),
$$

where $v_{g} \equiv v_{g}\left(\bar{D}_{g}\right)$ and $v_{i} \equiv v_{i}\left(\bar{D}_{i}\right)$ are the mean terminal velocities of the graupel particles and ice crystals, respectively. This implies that only the difference between the terminal velocities of graupel and ice particles is relevant in determining the current density. This expression is Galilean invariant, as can be shown by adding a vertical velocity $w$,

$$
j=\rho\left[\left(w+v_{g}\right)-\left(w+v_{i}\right)\right]=\rho\left(v_{g}-v_{i}\right),
$$

demonstrating that the generator-current density is not affected by the vertical motion of the ambient air (e.g., convective up- and downdrafts). The current density is positive because $\rho>0$ and $v_{g}>v_{i}$. Physically, this means that there is an upward flux of positive charge, which corresponds to positive (negative) charging of the upper (lower) regions of a thunderstorm if the ice (graupel) contains positive (negative) charge. Since $v_{i} \approx 0 \mathrm{~m} \mathrm{~s}^{-1}$,

$$
j \approx \rho v_{g}
$$

\section{REFERENCES}

Baker, B., M. B. Baker, E. R. Jayaratne, J. Latham, and C. P. R. Saunders, 1987: The influence of diffusional growth rates on the charge transfer accompanying rebounding collisions between ice crystals and soft hailstones. Quart. J. Roy. Meteor. Soc., 113, 1193-1215.

Baldauf, M., A. Seifert, J. Förstner, D. Majewski, M. Raschendorfer, and T. Reinhardt, 2011: Operational convective-scale numerical weather prediction with the COSMO model: Description and sensitivities. Mon. Wea. Rev., in press.

Betz, H.-D., K. Schmidt, P. Oettinger, and M. Wirz, 2004: Lightning detection with 3-D discrimination of intracloud and cloud-to-ground discharges. Geophys. Res. Lett., 31, L11108, doi:10.1029/2004GL019821.

,,-- P. Laroche, P. Blanchet, W. P. Oettinger, E. Defer, Z. Dziewit, and J. Konarski, 2009a: LINET-An international lightning detection network in Europe. Atmos. Res., 91, 564 573.

_ - , and P. Oettinger, 2009b: LINET_An international VLF/LF lightning detection network in Europe. Lightning: Principles, Instruments and Applications, H.-D. Betz, U. Schumann, and P. Laroche, Eds., Springer, 115-140.

Blyth, A. M., H. J. Christian, K. Driscoll, A. M. Gadian, and J. Latham, 2001: Determination of ice precipitation rates and thunderstorm anvil ice contents from satellite observations of lightning. Atmos. Res., 59, 217-229.

Boccippio, D., 2002: Lightning scaling relations revisited. J. Atmos. Sci., 59, 1086-1104.
Chèze, J., and H. Sauvageot, 1997: Area-average rainfall and lightning activity. J. Geophys. Res., 102, 1707-1716.

Cooke, C. M., E. R. Williams, and E. A. Wright, 1982: Electrical discharge propagation in space-charged PMMA. Proc. Conf. on Electrical Insulation, Philadelphia, PA, IEEE, 6059-6070.

Cooray, V., 1997: Energy dissipation in lightning flashes. J. Geophys. Res., 102, 21 401-21 410.

Dahl, J. M. L., H. Höller, and U. Schumann, 2011: Modeling the flash rate of thunderstorms. Part II: Implementation. Mon. Wea. Rev., 139, 3112-3124.

Dash, J. G., B. L. Mason, and J. S. Wettlaufer, 2001: Theory of charge and mass transfer in ice-ice collisions. J. Geophys. Res., 106, 20 395-20 402.

Deierling, W., W. Petersen, J. Latham, S. Ellis, and H. Christian, 2008: The relationship between lightning activity and ice fluxes in thunderstorms. J. Geophys. Res., 113, D15210, doi:10.1029/ 2007JD009700.

Doms, G., and U. Schättler, 2002: A description of the nonhydrostatic regional model LM. Part I: Dynamics and numerics. Deutscher Wetterdienst, 134 pp. [Available online at http://cosmo-model.org.]

Fehr, T., N. Dotzek, and H. Höller, 2005: Comparison of lightning activity and radar-retrieved microphysical properties in EULINOX storms. Atmos. Res., 76, 167-189.

Finke, U., 2009: Optical detection of lightning from space. Lightning: Principles, Instruments and Applications, H.-D. Betz, U. Schumann, and P. Laroche, Eds., Springer, 271-286.

Heymsfield, A., and M. Kajikawa, 1987: An improved approach to calculating terminal velocities of plate-like crystals and graupel. J. Atmos. Sci., 44, 1088-1099.

Höller, H., 1995: Radar-derived mass-concentrations of hydrometeors for cloud model retrievals. Preprints, 27th Conf. on Radar Meteorology, Vail, CO, Amer. Meteor. Soc., 453-454.

—, M. Hagen, P. F. Meischner, V. N. Bringi, and J. Hubbert, 1994: Life cycle and precipitation formation in a hybrid-type hailstorm revealed by polarimetric and Doppler radar measurements. J. Atmos. Sci., 51, 2500-2522.

Houze, R. A., Jr., 1993: Cloud Dynamics. International Geophysics Series, Vol. 53, Academic Press, 573 pp.

Huntrieser, H., and Coauthors, 2008: Lightning activity in Brazilian thunderstorms during TROCCINOX: Implications for $\mathrm{NO}_{x}$ production. Atmos. Chem. Phys., 8, 921-953.

Jacobson, E. A., and E. P. Krider, 1976: Electrostatic field changes produced by Florida lightning. J. Atmos. Sci., 33, 103-117.

Johns, R., and C. A. Doswell III, 1992: Severe local storms forecasting. Wea. Forecasting, 7, 588-612.

Kuhlman, K. M., C. L. Ziegler, E. R. Mansell, D. R. MacGorman, and J. M. Straka, 2006: Numerically simulated electrification and lightning of the 29 June 2000 STEPS supercell storm. Mon. Wea. Rev., 134, 2734-2757.

Larsen, H. R., and E. J. Stansbury, 1974: Association of lightning flashes with precipitation cores extending to height $7 \mathrm{~km}$. J. Atmos. Terr. Phys., 36, 1547-1553.

Lu, G., S. A. Cummer, J. Li, F. Han, R. J. Blakeslee, and H. J. Christian, 2009: Charge transfer and in-cloud structure of large-charge-moment positive lightning strokes in a mesoscale convective system. Geophys. Res. Lett., 36, L15805, doi:10.1029/ 2009GL038880.

MacGorman, D. R., and W. D. Rust, 1998: The Electrical Nature of Storms. Oxford University Press, 422 pp.

— J. M. Straka, and C. L. Ziegler, 2001: A lightning parameterization for numerical cloud models. J. Appl. Meteor., 40, 459-478. 
Maggio, C., T. Marshall, and M. Stolzenburg, 2009: Estimations of charge transferred and energy released by lightning flashes. J. Geophys. Res., 114, D14203, doi:10.1029/2008JD011506.

Mansell, E. R., D. R. MacGorman, C. L. Ziegler, and J. M. Straka, 2002: Simulated three-dimensional branched lightning in a numerical thunderstorm model. J. Geophys. Res., 107, 4075, doi:10.1029/2000JD000244.

,,--- and $\longrightarrow, 2005$ : Charge structure and lightning sensitivity in a simulated multicell thunderstorm. J. Geophys. Res., 110, D12101, doi:10.1029/2004JD005287.

McCaul, E., Jr., S. J. Goodman, K. M. LaCasse, and D. J. Cecil, 2009: Forecasting lightning threat using cloud-resolving model simulations. Wea. Forecasting, 24, 709-729.

Ogawa, T., 1995: Lightning currents. Handbook of Atmospheric Electrodynamics, Vol. 1, H. Volland, Ed., CRC Press, 93-136.

Phelps, C., 1974: Positive streamer system intensification and its possible role in lightning initiation. J. Atmos. Terr. Phys., 36, 103-111.

Price, C., and D. Rind, 1992: A simple lightning parameterization for calculating global lightning distributions. J. Geophys. Res., 97, 9919-9933.

Pruppacher, H. R., and J. D. Klett, 1997: Microphysics of Clouds and Precipitation. 2nd ed. Kluwer Academic Publishers, 954 pp.

Rakov, V. A., and M. A. Uman, 2003: Lightning: Physics and Effects. Cambridge University Press, $850 \mathrm{pp}$.

Saunders, C. P. R., 2008: Charge separation mechanisms in clouds. Space Sci. Rev., 137, 335-353.

Schroth, A. C., M. S. Chandra, and P. F. Meischner, 1988: A C-band coherent polarimetric radar for propagation and cloud physics research. J. Atmos. Oceanic Technol., 5, 803-822.

Shackford, C. R., 1960: Radar indications of a precipitation-lightning relationship in New England thunderstorms. J. Atmos. Sci., 17, $15-19$.

Shao, X. M., M. Stanley, A. Regan, J. Harlin, M. Pongratz, and M. Stock, 2006: Total lightning observations with the new and improved Los Alamos Sferic Array (LASA). J. Atmos. Oceanic Technol., 23, 1273-1288.

Stolzenburg, M., and T. C. Marshall, 2009: Electric field and charge structure in lightning-producing clouds. Lightning: Principles, Instruments and Applications, H.-D. Betz, U. Schumann, and P. Laroche, Eds., Springer, 57-82.

- W. D. Rust, B. F. Smull, and T. C. Marshall, 1998: Electrical structure in thunderstorm convective regions 1 . Mesoscale convective systems. J. Geophys. Res., 103, 14 059-14 078.

Takahashi, T., 1978: Riming electrification as a charge generation mechanism in thunderstorms. J. Atmos. Sci., 35, 1536-1548.

Tapia, A., J. A. Smith, and M. Dixon, 1998: Estimation of convective rainfall from lightning observations. J. Appl. Meteor., 37, 1497-1509.

Vonnegut, B., 1963: Some facts and speculations concerning the origin and role of thunderstorm electricity. Severe Local Storms, Meteor. Monogr., No. 27, Amer. Meteor. Soc., 224-241.

Wiens, K. C., S. A. Rutledge, and S. A. Tessendorf, 2005: The 29 June 2000 supercell observed during STEPS. Part II: Lightning and charge structure. J. Atmos. Sci., 62, 4151-4177.

Williams, E. R., 1985: Large-scale charge separation in thunderclouds. J. Geophys. Res., 90, 6013-6025.

, 1989: The tripole structure of thunderstorms. J. Geophys. Res., 94, 13 151-13 167.

2001: The electrification of severe storms. Severe Convective Storms, Meteor. Monogr., No. 50, Amer. Meteor. Soc., 527561.

— C. Cooke, and K. Wright, 1985: Electrical discharge propagation in and around space charge clouds. J. Geophys. Res., 90, 6059-6070

Yoshida, S., T. Morimoto, T. Ushio, and Z. Kawasaki, 2009: A fifthpower relationship for lightning activity from Tropical Rainfall Measuring Mission satellite observations. J. Geophys. Res., 114, D09104, doi:10.1029/2008JD010370.

Zipser, E. J., 1994: Deep cumulonimbus cloud systems in the tropics with and without lightning. Mon. Wea. Rev., 122, 1837-1851. 